\title{
Novel Cytocidal Substituted Phenyl 4-(2-0xoimidazolidin-1-yl) Benzenesulfonates and Benzenesulfonamides with Affinity to the Colchicine-Binding Site: Is the Phenyl 2-Imidazolidinone Moiety a New Haptophore for the Design of New Antimitotics?
}

\author{
Sébastien Fortin ${ }^{1,2 *}$, Lianhu Wei ${ }^{3,4}$, Lakshmi P. Kotra ${ }^{3,4}$, René C.-Gaudreault ${ }^{1,5^{*}}$ \\ ${ }^{1}$ Unité des Biotechnologies et de Bioingénierie, Centre de Recherche du CHU de Québec, Hôpital \\ Saint-François d'Assise, Université Laval, Québec, Canada \\ ${ }^{2}$ Faculté de Pharmacie, Université Laval, Pavillon Vandry, Québec, Canada \\ ${ }^{3}$ Department of Pharmaceutical Sciences, University of Toronto, Toronto, Canada \\ ${ }^{4}$ Center for Molecular Design and Preformulations, Toronto General Research Institute, University \\ Health Network, Toronto, Canada \\ ${ }^{5}$ Département de Médecine Moléculaire, Faculté de Médecine, Université Laval, Pavillon Vandry, \\ Québec, Canada \\ Email: "rene.c-gaudreault@crchudequebec.ulaval.ca,
}

Received 28 February 2015; accepted 20 March 2015; published 24 March 2015

Copyright $@ 2015$ by authors and Scientific Research Publishing Inc.

This work is licensed under the Creative Commons Attribution International License (CC BY).

http://creativecommons.org/licenses/by/4.0/

(c) () Open Access

\section{Abstract}

Phenyl 4-(2-oxoimidazolidin-1-yl)benzenesulfonates (PIB-SOs) and phenyl 4-(2-oxoimidazolidin1-yl)benzenesulfonamides (PIB-SAs) are new, potent combretastatin A-4 (CA-4) analogs designed on the basis of their common phenyl 2-imidazolidone moiety. This phenyl 2-imidazolidone group is a bioisosteric equivalent of the trimethoxyphenyl group also found in colchicine, podophyllotoxin and several other ligands of the colchicine-binding site (C-BS). In this study, we investigate the interactions involved in the binding of PIB-SO and PIB-SA into the C-BS. We describe three distinct pockets (I, II, and III) as key structural elements involved in the interactions between the

${ }^{*}$ Corresponding author.

How to cite this paper: Fortin, S., Wei, L.H., Kotra, L.P. and C.-Gaudreault, R. (2015) Novel Cytocidal Substituted Phenyl 4-(2-Oxoimidazolidin-1-yl) Benzenesulfonates and Benzenesulfonamides with Affinity to the Colchicine-Binding Site: Is the Phenyl 2-Imidazolidinone Moiety a New Haptophore for the Design of New Antimitotics? Open Journal of Medicinal Chemistry, 5, 9-22. http://dx.doi.org/10.4236/ojmc.2015.51002 
C-BS and PIB-SOs as well as PIB-SAs. We show that PIB-SOs and PIB-SAs adopt 4 and 3 distinct binding conformations, respectively, within the C-BS. The binding conformations I and IV are common to most PIB-SOs and PIB-SAs exhibiting high affinity for the C-BS and high cytocidal potency. In addition, binding conformation I is the main conformation adopted by PIB-SOs, PIB-SAs, T138067, ABT-751, colchicine and CA-4. We also observe that the sulfonate and the sulfonamide moieties of PIB-SOs and PIB-SAs are bioisosteric equivalents. Interestingly, we further find that a large portion of the phenyl 2-imidazolidinone moiety in these analogs does not bind to pocket I unlike the trimethoxyphenyl moiety found in several antimicrotubule agents such as colchicine, CA-4 and podophyllotoxin, suggesting that the phenyl 2-imidazolidinone group may represent a new haptophoric moiety useful for the design of new C-BS inhibitors mimicking the tropolone and the methoxylated phenolic moieties of colchicine and CA-4, respectively.

\section{Keywords}

Docking, Colchicine-Binding Site Ligands, Antimicrotubule Agents, PIB-SO, PIB-SA

\section{Introduction}

Cancer has recently become the leading cause of death in North America [1] [2] and worldwide [3]. Nowadays, cancers are responsible for $29 \%$ of all deaths as compared to $28 \%$ for cardiovascular diseases. In 2015, it is expected that approximately 1,658,370 Americans will be newly diagnosed with cancer and 589,430 will die from cancers or cancer-related causes [4]. A recent report states that the global burden of cancer will increase by $>75 \%$ by 2030 [1]. Therefore, cancer research must be pursued on all fronts to improve both the quality of life and life expectancy. In this context, chemotherapeutic drugs are an option of steadily increasing importance, especially for systemic malignancies and metastatic cancers [5]-[10].

Vascular disrupting agents (VDAs) are a relatively new class of anticancer drugs that target tumor vasculature, thereby causing an interruption of tumor blood flow and necrosis of the tumor mass [11] [12]. Several VDAs are currently under clinical development for cancer, including the lead compound combretastatin A-4 (CA-4, 1) and its water-soluble, disodium phosphate prodrug form (CA-4P, 2) [12]-[14], as well as T138067 (3) [15] and ABT-751 (4) [16] (Figure 1). CA-4 is a stilbenoid phenol isolated from the bark of the South African Bushwillow tree, Combretum caffrum. CA-4 and its prodrugs are antimicrotubule agents that bind to the colchicinebinding site (C-BS) [17] [18] and selectively target endothelial cells, thereby inducing the regression of unstable emerging tumor neovessels through interference with vascular endothelial-cadherin signaling [19]. CA-4P has recently received an orphan drug designation for the treatment of anaplastic thyroid cancer, medullary thyroid cancer and stage IV papillary or follicular thyroid cancer. However, CA-4P exhibits significant side effects such as hypertension, hypotension, tachycardia, tumor-related pain, and lymphopenia [13]. Despite promising results, the biopharmaceutical and anticancer properties of CA-4P are suboptimal and in need of improvement. Thus, there is still a clear demand for new CA-4P analogues and derivatives.

The structure-activity relationships of CA-4 have been extensively studied, and $>28,000$ derivatives and analogs have been synthesized and biologically evaluated to date [20]. The chemical structure of CA-4 is usually partitioned into three main moieties, namely the trimethoxyphenyl group (ring $\mathrm{A}$ ), a methoxylated phenolic moiety (ring B) and the ethenyl bridge linking rings A and B (Figure 1). Ring B and the ethenyl bridge have been the most studied to date. Early structure-activity relationship (SAR) studies have clearly suggested that only few modifications of ring A are compatible with potent antimitotics. Thus, most modifications of combretastatins have been directed to ring B and the ethenyl bridge. Modifications of ring B have included, but have not been limited to, different substitutions on the phenyl, heteroaromatic or heterocyclic rings [21]-[24], and the unstable ethenyl bridge is substituted either with sulfonate (Figure 1) [25] [26], chalcone [27] [28], imidazole [29], triazole [30] [31], furazan [32], pyrazole or 1,3-thiazole [33] derivatives.

Previous SAR studies in our laboratory have demonstrated that both $N$-phenyl- $N$ '-(2-chloroethyl)ureas (5a-5d) and their phenyl 2-aminoxazoline (6a, $\mathbf{6 b}$ ) bioisosteric equivalents (Figure 1) could replace the 3,4,5-trimethoxyphenyl moiety (ring A) of CA-4 and bind to the C-BS with similar spatial conformations [34]-[42]. To further assess the potential of the $N$-phenyl- $N$ '-(2-chloroethyl)urea moiety for the development of new VDAs derived from CA-4, we develop analogues with low-molecular weight derived from substituted phenyl 4-(2- 
<smiles>[R]Oc1cc(/C=C\c2cc(OC)c(OC)c(OC)c2)ccc1OC</smiles>

1: $\mathrm{R}=\mathrm{H}(\mathrm{CA}-4)$

2: $\mathrm{R}=\mathrm{PO}_{3} \mathrm{Na}_{2}(\mathrm{CA}-4 \mathrm{P})$<smiles>[R][X]1([H])CCCCC1</smiles>

5a: 4-tert-butyl (tBCEU)

5b: 4-lodo (ICEU)

5c: 3-(5-hydroxypentyl) (HPCEU)

5d:<smiles>C=Cc1ccc(OC)c(O)c1</smiles>

(4ZCombCEU)<smiles>COc1ccc(NS(=O)(=O)c2c(F)c(F)c(F)c(F)c2F)cc1F</smiles>

3: T138067<smiles>[R]c1ccc(NC2=NCCO2)cc1</smiles>

6a: 4-tert-butyl (tBOXA) 6b: 4-lodo (IOXA)<smiles>COc1ccc(S(=O)(=O)Nc2cccnc2Nc2ccc(O)cc2)cc1</smiles>

4: ABT-751<smiles></smiles>

7: Colchicine<smiles>[R]C=COc1ccccc1OS(=O)(=O)c1ccc(N2CCNC2=O)cc1</smiles>

9-67: PIB-SOs<smiles></smiles>

A8-A48: PIB-SAs

Figure 1. Molecular structure of CA-4 (1), CA-4P (2), T138067 (3), ABT-751 (4), $N$-phenyl- $N$ '-(2-chloroethyl)ureas (5a-5d), phenyl 2-aminooxazoline (6a, 6b), colchicine (7), TN-16 (8), PIB-SOs (9-67) and PIB-SAs (A8-A48).

oxoimidazolidin-1-yl)benzenesulfonates (PIB-SOs, 9-67) [43] and phenyl 4-(2-oxoimidazolidin-1-yl)benzenesulfonamides (PIB-SAs, A8-A48) [44], where the 2-chloroethylurea moiety is cyclized under basic conditions into the corresponding 2-imidazolidone ring. We prepare more than 100 derivatives and screen for their antiproliferative activities. PIB-SOs and PIB-SAs exhibit antiproliferative activities at the nanomolar level towards several tumor cell lines, bind to the C-BS, block cell cycle progression in G2-M phase, disrupt the cytoskeleton and show potent antineoplastic activity towards human fibrosarcoma (HT-1080) tumors grafted onto the chorioallantoic membrane of developing chicks, and low systemic toxicity towards the embryos [43] [44]. Based on SAR studies of $N$-phenyl- $N$ '-(2-chloroethyl)ureas [34]-[42], we hypothesize that the phenyl 2-imidazolidinone moiety of PIB-SOs and PIB-SAs might also mimic the 3,4,5-trimethoxyphenylated ring A of CA-4 and could be used as a bioisosteric equivalent for the development of new VDAs derived from CA-4.

We investigate the key interacting elements of PIB-SOs and PIB-SAs and their spatial conformations when bound to the C-BS to understand the structure-activity relationships. Here, we reveal binding pockets and the amino acid residues are essential for the docking of PIB-SOs and PIB-SAs to the C-BS. Additionally, we also disclose the common binding sites and potential correlations with the factors for the antiproliferative activities using the spatial conformations of PIB-SOs and PIB-SAs as well as other inhibitors of the C-BS including CA-4 (1), T138067 (3), ABT-751 (4), colchicine (7) and TN-16 (8). Finally, our computational modeling results will be beneficial for the design of novel antimicrotubule agents targeting the C-BS.

\section{Results and Discussion}

\subsection{Assessment of the Surflex-Dock ${ }^{\mathrm{TM}}$ Technique as Applied to the C-BS}

Surflex-Dock ${ }^{\mathrm{TM}}$ uses an empirical scoring function and docks ligands into a protein-binding site. The Surflex- 
Dock ProtoMol is a computational representation of the intended binding site against which putative ligands are aligned. The ProtoMol is not meant to be an absolute docking envelope but its purpose is to direct the initial placement of the ligand during the docking process. Docked ligands are scored in the context of the receptor, not in the context of the ProtoMol [45]. To evaluate this docking technique with the C-BS, we used Surflex-Dock to dock selected inhibitors, namely T138067, ABT-751, colchicine and TN-16, as extracted from their X-ray structure in complex with the C-BS (protein data bank (PDB): 3HKE [46] for T138067, 3HKC [46] for ABT751, 1SA0 [47] for colchicine and 3HKD [46] for TN-16) into the corresponding receptor binding site in silico (Figure 2). A reasonable agreement was obtained between the conformation proposed from the docking expe-

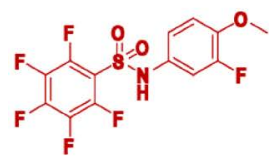

3: T138067

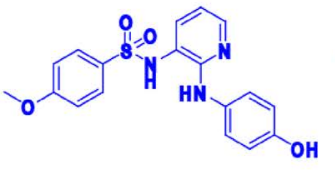

4: $\mathrm{ABT}-751$

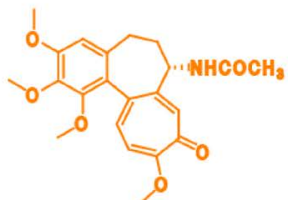

7: Colchicine

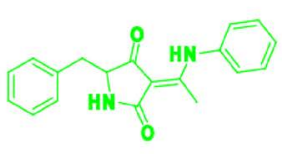

8: $\mathrm{TN}-16$

(a)

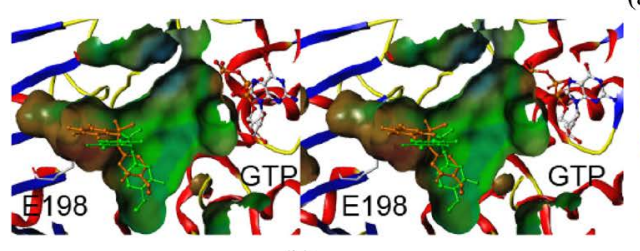

(b)

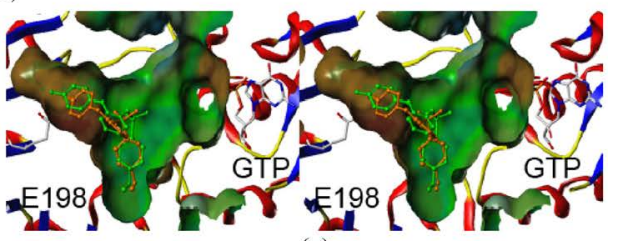

(c)

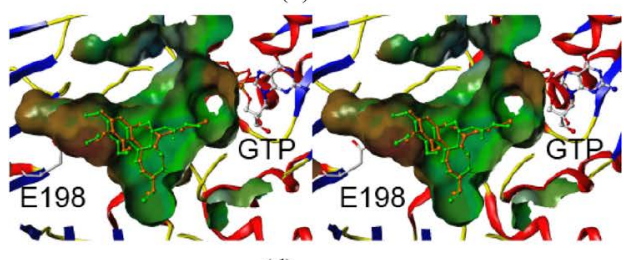

(d)

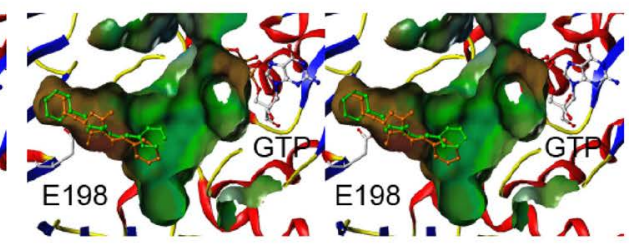

(e)

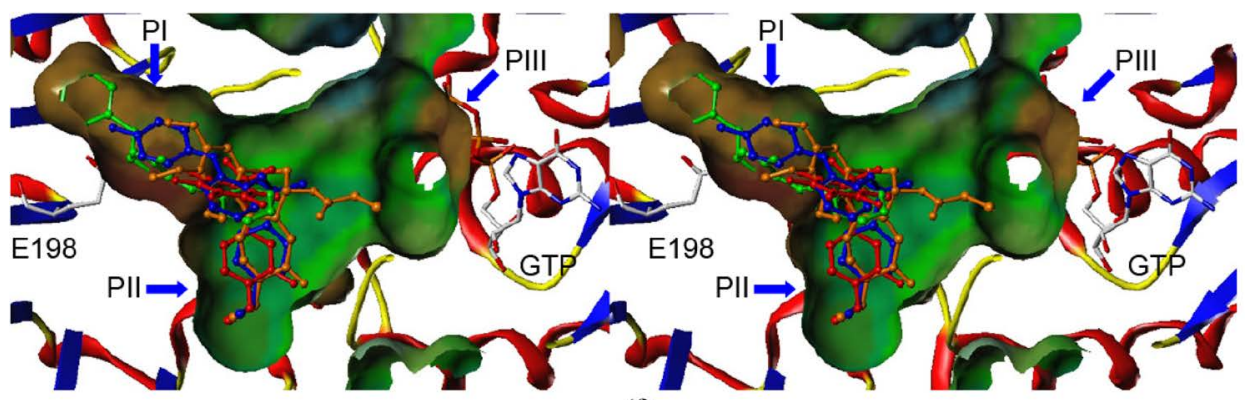

(f)

Figure 2. Stereo view of tubulin binding pockets and comparison of the re-docked conformations of inhibitors with their original conformation as obtained from crystal structures. Tubulin structure was presented as a cartoon model. The binding site was shown as a Connolly surface with hydrophobic properties (brown: hydrophobic; blue: hydrophilic; green: intermediate). (a) Molecular structures of T138067 (3), ABT-751 (4), colchicine (7) and TN-16 (8); (b) Docked T138067 binding conformation (orange ball-and-stick model) and conformation from crystal structure (green ball- and-stick model); (c) Docked ABT-751 binding conformation (orange ball-and-stick model) and conformation from crystal structure (green ball-and-stick model); (d) Docked colchicine binding conformation (orange ball-and-stick model) and conformation from crystal structure (green ball-and-stick model); (e) Docked TN-16 binding conformation (orange ball-and-stick model) and conformation from crystal structure (green ball-and-stick model); (f) C-BS inhibitor structures as determined from $\mathrm{X}$-ray crystallographic structure. T138067 (PDB: 3HKE) [46] is described as a red ball-and-stick model. ABT-751 (PDB: 3HKC) [46] is depicted as a blue ball-and-stick model. Colchicine (PDB: 1SA0) [47] is presented as an orange ball-and-stick model. TN-16 (PDB: 3HKD) [46] is shown as a green ball- and-stick model. Pocket I, II and III is defined as PI, PII and PIII, respectively. 
riment and that extracted from the X-ray co-crystal structure published for these inhibitors. A stereo view of the C-BS docked with the crystal structure of the four inhibitors is shown in Figures 2(b)-(e). According to the Surflex-Dock binding score, the highest score conformations of T138067, ABT-751 and colchicine had the closest conformations compared to crystal structures. Nonetheless, the closest conformation of TN-16 had the fourth highest score compared to the crystal structure. The latter result showed that there was a significant discrepancy between the conformation of bound TN-16 proposed from the docking simulation approach and that derived from its crystal structure, although the binding of TN-16 was rather unique among the C-BS inhibitors tested. Indeed, this is the only inhibitor that binds deeply inside the pocket I of C-BS (Figure 2(e)) and that involves hydrogen bonding between V238 and the pyrrolidine moiety of TN-16. Pockets I, II and III (PI, PII and PIII) of C-BS are described in Figure 2(f). Taken together, these results show that Surflex-Dock is a reliable technique to evaluate the docking conformation of the C-BS inhibitors, and can be used to assess the docking conformation of PIB-SOs and PIB-SAs in the C-BS.

\subsection{Validation of Inhibitors Binding Conformations to Tubulin}

T138067, ABT-751, colchicine and TN-16 are known potent inhibitors to C-BS. We therefore used these model ligands to determine the shape and the key amino acids lining up the binding pockets that are part of the C-BS. Of note, colchicine and CA-4 have the same trimethoxyphenyl pharmacophore group (ring A) and the same spatial conformation upon binding to the C-BS [48] [49]. For the sake of brevity, only data for colchicine will be presented. First, the C-BS has a large hydrophobic pocket with a triangular shape (Figure 2). C-BS inhibitors exploit different features of the binding site virtually across the whole surface of the binding site. C-BS inhibitors are found to bind to three distinct pockets of the C-BS (I, II and III, Figure 2(f)). V236, T237, Y200, I370, F266, F167, E198, N165, L250, and L253 residues constitute pocket I (PI, Figure 2(f)); residues K352, A316, V315, V351, T314, N350, M257, N256, and V181 surround pocket II (PII, Figure 2(f)); and residues near bound GTP, including GTP itself, namely T179, L246, K252, N101, A180, N247, and Q11, border pocket III (PIII, Figure 2(f)). The pockets I and II are the main regions to which the four aforementioned inhibitors bind, whereas the involvement of the pocket III is limited to the binding of the acetamido group of colchicine. Moreover, no C-BS inhibitor binds deeply within the binding site due to steric hindrance of this pocket, with the exception of TN-16, as indicated above.

\subsection{Docking Studies of PIB-SO and PIB-SA Derivatives}

PIB-SOs and PIB-SAs are two novel classes of C-BS inhibitors analogous to CA-4. We hypothesized that the new phenyl 2-imidazolidinone haptophore (or ring A) and ring B of PIB-SOs and PIB-SAs should mimic rings A (trimethoxyphenyl moiety) and B of CA-4 (Figure 1), respectively. Moreover, we also postulated that the sulfonate and sulfonamide moieties would replace the ethenyl bridge of CA-4 as shown by other groups [25] [26] [50] [51]. To assess this hypothesis and have an overview of the binding of this novel class of C-BS inhibitors, several PIB-SOs and PIB-SAs were docked into the C-BS using the Surflex-Dock approach. For easier cross-referencing, we use the same code numbers for PIB-SOs and PIB-SAs as in our previous publications [43] [44]. However, to avoid confusion in the code numbers between PIB-SOs and PIB-SAs, PIB-SA code numbers are preceded with an "A". The chemical structures of the PIB-SOs and PIB-SAs used in this study are shown in Table 1.

The PIB-SOs and PIB-SA poses obtained from the docking studies are shown in Table 2 and in Figure 3 and Figure 4. PIB-SOs and PIB-SAs adopted four and three docking conformations in the C-BS, respectively. PIBSOs $9,10,12,13,14,15,17,18,19,21,24,27,28,29,34,37,40,43,45,46,49,55,65,66$ and 67 adopted conformation I; 11, 26, 39 and 53 adopted conformation II; 32, 38, 41, 42, 50, 51 and 64 adopted conformation III; and 25, 30, 31, 44, 47, 48, 52, 61 and 62 adopted conformation IV. PIB-SAs A17, A25, A26, A30, A31, A35, A36, A42, A47 and A48 adopted conformation I; A8, A12, A28, A39, A40, A41, A45 and A46 adopted conformation IV; and A10, A21, A23 and A32 adopted conformation V. Docked conformation I for PIB-SOs and PIB-SAs is similar to that determined for T138067 and ABT-751 in X-ray crystallographic structures 3HKE and 3HKC, respectively, when bound to tubulin C-BS (docking conformation I in Table 2, and Figures 3(a)-(b), Figures 4(a)-(b)). Twenty-five PIB-SO and ten PIB-SA derivatives showed similarities to docking conformation I upon adopting their highest binding score conformations. In this binding conformation, the sulfonate or sulfonamide group is positioned at the center of the binding pocket, and the remainder of the structure extends 
Table 1. Molecular structures of PIB-SOs and PIB-SAs used in docking studies.

\begin{tabular}{|c|c|c|c|c|}
\hline $\begin{array}{c}\text { Code } \\
\text { numbers }{ }^{\mathrm{a}, \mathrm{b}}\end{array}$ & $\mathbf{R}$ or $\mathbf{R}_{1}$ & $\mathbf{X}$ & $\begin{array}{c}\mathrm{IC}_{50} \\
(\mathrm{MCF7}, \mathrm{nM})\end{array}$ & Competition assay \\
\hline 9 & $\mathrm{R}=2-\mathrm{Me}$ & $\mathrm{O}$ & 30 & ++ \\
\hline 10 & $\mathrm{R}=3-\mathrm{Me}$ & $\mathrm{O}$ & 57 & +++ \\
\hline 11 & $\mathrm{R}=4-\mathrm{Me}$ & $\mathrm{O}$ & 150 & - \\
\hline 12 & $\mathrm{R}=4-\mathrm{OMe}$ & $\mathrm{O}$ & 160 & + \\
\hline 13 & $\mathrm{R}=4-\mathrm{NMe}_{2}$ & $\mathrm{O}$ & 500 & N/A \\
\hline 14 & $\mathrm{R}=4-\mathrm{OH}$ & $\mathrm{O}$ & $>1000$ & N/A \\
\hline 15 & $\mathrm{R}=\mathrm{H}$ & $\mathrm{O}$ & $>1000$ & N/A \\
\hline 17 & $\mathrm{R}=$ 2-Prop & $\mathrm{O}$ & 69 & + \\
\hline 18 & $\mathrm{R}=2-\mathrm{OMe}$ & $\mathrm{O}$ & 220 & N/A \\
\hline 19 & $\mathrm{R}=2-\mathrm{OEt}$ & $\mathrm{O}$ & 83 & +++ \\
\hline 21 & $R=2-F$ & $\mathrm{O}$ & 61 & ++ \\
\hline 24 & $\mathrm{R}=2-\mathrm{Me}, 3-\mathrm{Me}$ & $\mathrm{O}$ & 50 & +++ \\
\hline 25 & $\mathrm{R}=2-\mathrm{Me}, 4-\mathrm{Me}$ & $\mathrm{O}$ & 50 & + \\
\hline 26 & $\mathrm{R}=2-\mathrm{Me}, 5-\mathrm{Me}$ & $\mathrm{O}$ & 14 & +++ \\
\hline 27 & $\mathrm{R}=2-\mathrm{Me}, 4-\mathrm{Me}, 5-\mathrm{Me}$ & $\mathrm{O}$ & 66 & ++ \\
\hline 28 & $\mathrm{R}=2-\mathrm{Cl}, 4-\mathrm{Cl}, 5-\mathrm{Cl}$ & $\mathrm{O}$ & 30 & +++ \\
\hline 29 & $\mathrm{R}=2-\mathrm{Cl}, 4-\mathrm{Cl}, 6-\mathrm{Cl}$ & $\mathrm{O}$ & 170 & N/A \\
\hline 30 & $\mathrm{R}=2-\mathrm{F}, 4-\mathrm{F}$ & $\mathrm{O}$ & 55 & ++ \\
\hline 31 & $\mathrm{R}=2-\mathrm{F}, 6-\mathrm{F}$ & $\mathrm{O}$ & 32 & +++ \\
\hline 32 & $\mathrm{R}=2-\mathrm{F}, 3-\mathrm{F}, 4-\mathrm{F}, 5-\mathrm{F}, 6-\mathrm{F}$ & $\mathrm{O}$ & 320 & N/A \\
\hline 34 & $\mathrm{R}=3-\mathrm{OMe}$ & $\mathrm{O}$ & 34 & +++ \\
\hline 37 & $\mathrm{R}=3-\mathrm{F}$ & $\mathrm{O}$ & 54 & ++ \\
\hline 38 & $R=3-I$ & $\mathrm{O}$ & 18 & +++ \\
\hline 39 & $\mathrm{R}=3-\mathrm{NO}_{2}$ & $\mathrm{O}$ & 60 & +++ \\
\hline 40 & $\mathrm{R}=3-\mathrm{NH}_{2}$ & $\mathrm{O}$ & 270 & N/A \\
\hline 41 & $\mathrm{R}=3-\mathrm{Me}, 5-\mathrm{Me}$ & $\mathrm{O}$ & 47 & +++ \\
\hline 42 & $\mathrm{R}=3-\mathrm{Me}, 4-\mathrm{Me}, 5-\mathrm{Me}$ & $\mathrm{O}$ & 49 & +++ \\
\hline 43 & $\mathrm{R}=3-\mathrm{OMe}, 4-\mathrm{OMe}$ & $\mathrm{O}$ & 88 & +++ \\
\hline 44 & $\mathrm{R}=3-\mathrm{OMe}, 5-\mathrm{OMe}$ & $\mathrm{O}$ & 10 & +++ \\
\hline 45 & $\mathrm{R}=$ 3-OMe, 4-OMe, 5-OMe & $\mathrm{O}$ & 5.0 & +++ \\
\hline 46 & $\mathrm{R}=3-\mathrm{Cl}, 5-\mathrm{Cl}$ & $\mathrm{O}$ & 18 & +++ \\
\hline 47 & $\mathrm{R}=3-\mathrm{F}, 4-\mathrm{F}$ & $\mathrm{O}$ & 100 & + \\
\hline
\end{tabular}




\section{Continued}

\begin{tabular}{|c|c|c|c|c|}
\hline & & & & \\
\hline 48 & $\mathrm{R}=3-\mathrm{F}, 5-\mathrm{F}$ & $\mathrm{O}$ & 47 & +++ \\
\hline 49 & $\mathrm{R}=3-\mathrm{F}, 4-\mathrm{F}, 5-\mathrm{F}$ & $\mathrm{O}$ & 91 & + \\
\hline 50 & $\mathrm{R}=3-\mathrm{Me}, 4-\mathrm{NO}_{2}$ & $\mathrm{O}$ & 180 & N/A \\
\hline 51 & $\mathrm{R}=3-\mathrm{Me}, 4-\mathrm{NH}_{2}$ & $\mathrm{O}$ & 600 & N/A \\
\hline 52 & $\mathrm{R}_{2}=4-\mathrm{Et}$ & $\mathrm{O}$ & 190 & N/A \\
\hline 53 & $\mathrm{R}=4$-Prop & $\mathrm{O}$ & 110 & + \\
\hline 55 & $\mathrm{R}=4-\mathrm{OE} \mathrm{t}$ & $\mathrm{O}$ & 56 & + \\
\hline 61 & $\mathrm{R}=4-\mathrm{I}$ & $\mathrm{O}$ & 210 & N/A \\
\hline 62 & $\mathrm{R}=4-\mathrm{NO}_{2}$ & $\mathrm{O}$ & $>1000$ & N/A \\
\hline 64 & $\mathrm{R}_{1}=$ & - & 330 & N/A \\
\hline 65 & $\mathrm{R}_{1}=\mathrm{O}$ & - & 100 & +++ \\
\hline 66 & $\mathrm{R}_{1}=\mathrm{O}_{Y}$ & - & 770 & N/A \\
\hline 67 & $\mathrm{R}_{1}=$ & - & $>1000$ & N/A \\
\hline A8 & $\mathrm{R}=\mathrm{H}$ & $\mathrm{NH}$ & 470 & N/A \\
\hline A10 & $\mathrm{R}=2-\mathrm{Et}$ & $\mathrm{NH}$ & 350 & N/A \\
\hline A12 & $\mathrm{R}=2-\mathrm{Me}, 3-\mathrm{Me}$ & $\mathrm{NH}$ & 230 & N/A \\
\hline A17 & $\mathrm{R}=3-\mathrm{OMe}$ & $\mathrm{NH}$ & 120 & +++ \\
\hline A21 & $\mathrm{R}=3-\mathrm{Me}, 4-\mathrm{Me}$ & $\mathrm{NH}$ & 230 & N/A \\
\hline A23 & $\mathrm{R}=3-t$ But, $5-t$ But & $\mathrm{NH}$ & $>1000$ & N/A \\
\hline A25 & $\mathrm{R}=3-\mathrm{OMe}, 4-\mathrm{OMe}$ & $\mathrm{NH}$ & 610 & N/A \\
\hline A26 & $\mathrm{R}=3-\mathrm{OMe}, 5-\mathrm{OMe}$ & $\mathrm{NH}$ & 170 & +++ \\
\hline A28 & $\mathrm{R}=4-\mathrm{Me}$ & $\mathrm{NH}$ & 610 & N/A \\
\hline A30 & $\mathrm{R}=4-\mathrm{But}$ & $\mathrm{NH}$ & 770 & N/A \\
\hline A31 & $\mathrm{R}=4-\sec \mathrm{But}$ & $\mathrm{NH}$ & $>1000$ & N/A \\
\hline A32 & $\mathrm{R}=4-\mathrm{tBut}$ & $\mathrm{NH}$ & $>1000$ & N/A \\
\hline A35 & $\mathrm{R}=4-\mathrm{Hept}$ & NH & $>1000$ & N/A \\
\hline A36 & $\mathrm{R}=4-\mathrm{OMe}$ & $\mathrm{NH}$ & $>1000$ & N/A \\
\hline A39 & $\mathrm{R}=4-\mathrm{Br}$ & $\mathrm{NH}$ & 240 & N/A \\
\hline A40 & $\mathrm{R}=4-\mathrm{Cl}$ & $\mathrm{NH}$ & 170 & N/A \\
\hline A41 & $\mathrm{R}=4-\mathrm{F}$ & $\mathrm{NH}$ & 690 & N/A \\
\hline A42 & $\mathrm{R}=4-\mathrm{I}$ & $\mathrm{NH}$ & 600 & N/A \\
\hline A45 & $\mathrm{R}_{1}=\mathrm{H}$ & $\mathrm{NH}$ & 460 & N/A \\
\hline A46 & $\mathrm{R}_{1}=\mathrm{HN}$ & NH & 480 & N/A \\
\hline A47 & $\mathrm{R}_{1}=\mathrm{HN}^{-}$ & $\mathrm{NH}$ & 240 & N/A \\
\hline A48 & $\mathrm{R}_{1}=\mathrm{HN}^{\mathcal{X}}$ & $\mathrm{NH}$ & 170 & ++ \\
\hline
\end{tabular}

${ }^{\mathrm{a}}$ The compound code numbers of PIB-SOs and PIB-SAs refer to our previous publications [43] [44]. ${ }^{\mathrm{b}}$ To avoid confusion in code numbers between PIB-SOs and PIB-SAs, the prefix $A$ has been added at the beginning of PIB-SA the code numbers. ${ }^{c}$ N/A: Not available. 
Table 2. Docking poses of the PIB-SO and PIB-SA derivative series.

\begin{tabular}{|c|c|c|c|c|c|}
\hline Docking pose & I & $\mathrm{II}^{\mathrm{a}}$ & $\mathrm{III}^{\mathrm{a}}$ & IV & $\mathrm{V}^{\mathrm{a}}$ \\
\hline PIB-SO derivatives & $\begin{array}{c}9,10,12,13,14,15,17,18,19,21 \\
24,27,28,29,34,37,40,43,45,46 \\
49,55,65,66,67\end{array}$ & $\begin{array}{l}11,26 \\
39,53\end{array}$ & $\begin{array}{c}32,38,41,42,50 \\
51,64\end{array}$ & $\begin{array}{c}25,30,31,44,47 \\
48,52,61,62\end{array}$ & - \\
\hline PIB-SA derivatives & $\begin{array}{c}\text { A17, A25, A26, A30, A31, A35, A36, } \\
\text { A42, A47, A48 }\end{array}$ & - & - & $\begin{array}{l}\text { A8, A12, A28, } \\
\text { A39, A40, A41, } \\
\text { A45, A46 }\end{array}$ & $\begin{array}{c}\text { A10, } \\
\text { A21, } \\
\text { A23, A32 }\end{array}$ \\
\hline
\end{tabular}

${ }^{a}$ No derivative in the docking pose.

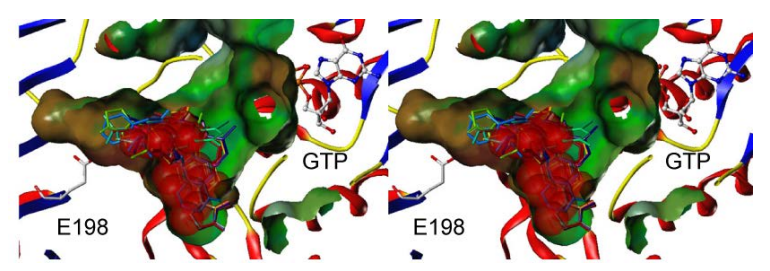

(a)

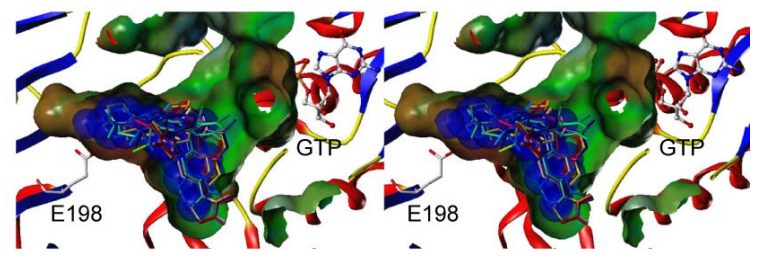

(b)

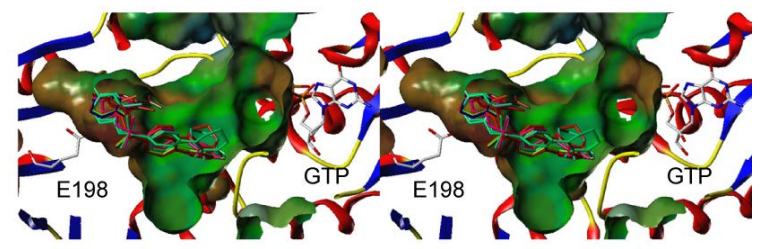

(c)

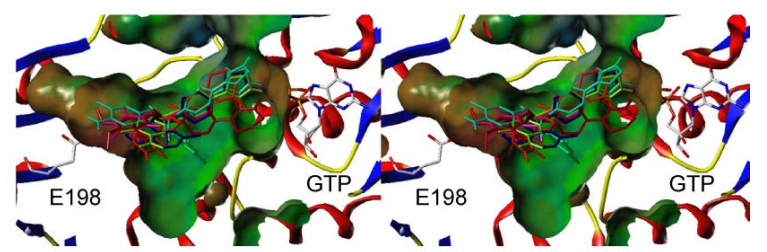

(d)

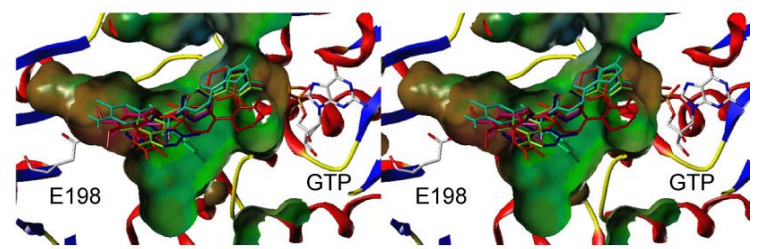

(e)

Figure 3. Stereo view of the docking conformations of selected PIB-SOs to tubulin. (a) and (b) Overlapping the docking conformations of 25 PIB-SO derivatives with the X-ray crystallographic structures of reference C-BS inhibitors shows that they share pose I, which is similar to the crystal structure conformations adopted by (a) T138067 and (b) ABT-751 upon binding to the C-BS. PIB-SO compounds are presented as capped-stick models. For comparison, the T138067 conformation in PDB 3HKE is presented as a transparent space-filled model colored in red (panel (a)). The ABT-751 conformation in PDB 3HKC is presented as a transparent space-filled model colored in blue (panel B). The other three major docking poses (II, III, and IV) adopted by PIB-SO derivatives are shown in panels (c)-(e), respectively. 
into the pockets I and II. In Figure 3(a) and Figure 4(a), T138067 was used as a reference to compare the docking conformations of PIB-SO and PIB-SA derivatives. In Figure 3(b) and Figure 4(b), the binding conformation of ABT-751 is illustrated for comparison with the PIB-SO and PIB-SA derivatives shown in conformation I. The 4 PIB-SOs with the highest scores upon docking fell into docked pose II. In the latter conformation, the sulfonate group is moved toward the pocket $\mathrm{I}$, with one extremity of the molecule deeply extending into the bottom of pocket I and the other end extending towards the center of the C-BS (Figure 3(c)). Figure 3(d) shows docking conformation III in the C-BS, which was mimicked by 7 PIB-SO derivatives with the highest docking scores and where the structures extend from pocket I to pocket III. With docking conformation IV, the sulfonate and sulfonamide moieties of PIB-SO and PIB-SA derivatives, respectively, were found to overlap in pocket II and assumed a bent conformation spanning the middle of the C-BS (Figure 3(e) and Figure 4(c)). The two ends of the 9 PIB-SO and 8 PIB-SA derivatives are found to fold in towards the middle of the C-BS. Finally, four compounds in the PIB-SA series share a completely different docking conformation V (Figure 4(d)) wherein

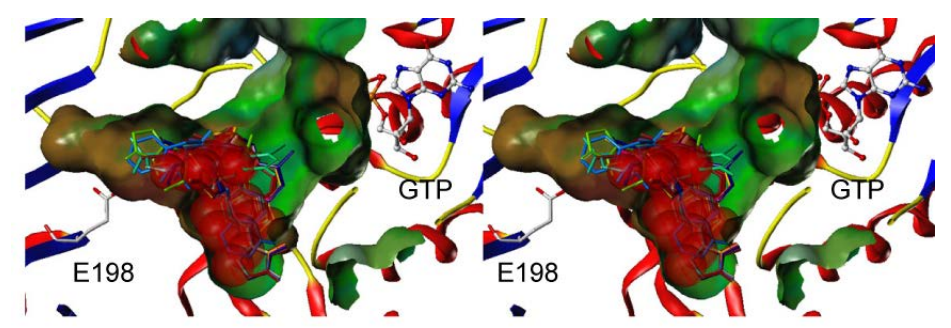

(a)

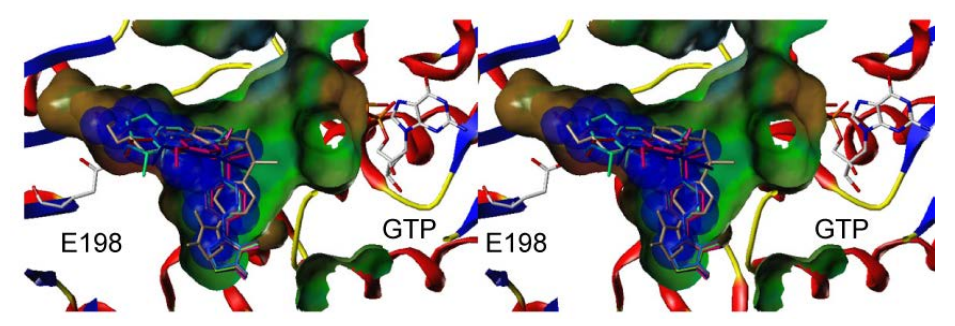

(b)

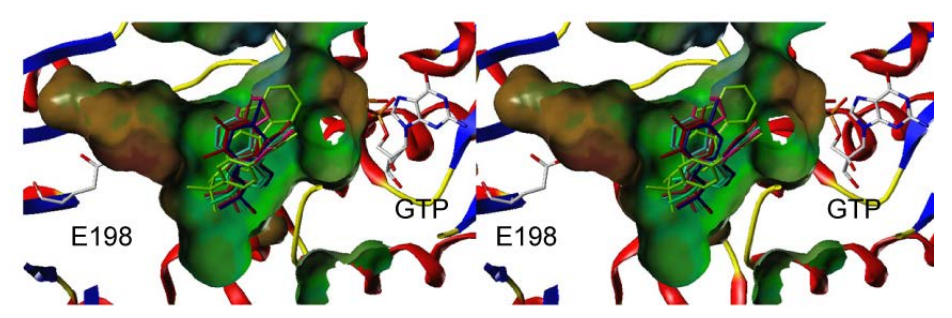

(c)

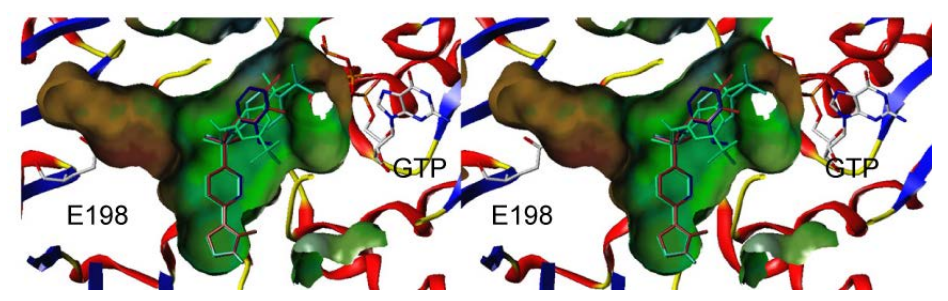

(d)

Figure 4. (a) and (b) Overlapping the docking conformations of 10 PIB-SA derivatives with the X-ray crystallographic structure of C-BS inhibitors shows that they share pose I, which is similar to (a) T138067 and (b) ABT-751 conformations in crystal structures. PIB-SA compounds were presented as capped-stick models. For comparison, the T138067 conformation in PDB 3HKE is presented as a transparent space-filled model colored in red (panel (a)). The ABT-751 conformation in PDB 3HKC is presented as a transparent space-filled model colored in blue (panel (b)). Panel (c) shows the other major docking pose, namely pose IV, and panel (d) illustrates the minor docking pose V adopted by PIB-SA derivatives. 
the phenylimidazolidin-2-one and sulfonamide moieties extend into the pocket II and, interestingly, phenyl ring B extends into the pocket III next to GTP.

\subsection{Structures, Spatial Conformations, and Affinities of PIB-SOs and PIB-SAs in the C-BS}

Based on the docking studies of PIB-SO and PIB-SA derivatives, the general structure of PIB-SOs adopt conformation I when ring B is mono- or disubstituted with small alkyl groups at positions 2 and 3 or mono- or disubstituted with alkoxy or halogen groups at positions 3 and 4. Generally, for the PIB-SAs to adopt conformation I, ring B must be substituted by an alkyl chain at position 4 or mono- or disubstituted by alkoxy groups at positions 3 and 4. On the other hand, no clear structural rules can be defined that promotes the adoption of conformations II-IV by the various PIB-SOs and PIB-SAs. Indeed, minor structural changes such as elongation of the alkyl chain at position 4 (e.g. 11, 52 and 53) and the position of 2 or more identical groups on the ring (e.g. 25, 26, 41 and 42) modify conformation upon binding to the C-BS. These constraints result from the spatial limitations within the C-BS, which entail important steric hindrance.

PIB-SOs and PIB-SAs adopt two identical major docking conformations, namely I and IV, where the sulfonate and sulfonamide moieties are approximately in the same position. Moreover, except for conformation II, the sulfonate and sulfonamide moieties tend to occupy the center of the C-BS in most high-scoring binding conformations, such as the ethenyl bridge of CA-4. In addition, in most docking conformations, the phenyl 2-imidazolidinone moiety of PIB-SOs and PIB-SAs is stabilized by pocket II of the C-BS, in which it fits rather closely. The remaining portion of these drugs fits mostly into the pocket I, although a portion of the molecule extends into the pocket III in a few cases. Therefore, the phenyl 2-imidazolidinone moiety appears to mimic the 2-methoxyphenol and the tropolone moieties (ring B) of CA-4 and colchicine, respectively, but not the 3,4,5trimethoxyphenyl moiety (ring A) of CA-4. Finally, both pockets I and II are large enough to accommodate larger substitutions. Thus long hydrophobic substituents may fit better in pocket I whereas bulky albeit more compact groups might be preferred for the pocket III. For the derivatives studied herein, the substituent shape is more important than other properties such as hydrogen bonding, salt bridge formation, or electrostatic interaction since the binding pocket is clearly hydrophobic, and the most likely ligand-receptor interactions to occur are mostly driven by van der Waals forces rather than ionic or other polar forces.

Interestingly, in the PIB-SO and PIB-SA series, compounds with the strongest antiproliferative activity and affinity for the C-BS almost all bind when adopting either conformation I or IV. Moreover, the docking conformation I is the main spatial conformation adopted by PIB-SOs, PIB-SAs as well as other potent C-BS inhibitors such as T138067, ABT-751, colchicine and CA-4. This result thus confirms the model and its use to assess and predict some of the structure-activity requirements for the next generation of PIB-SOs and PIB-SAs.

\section{Conclusion}

We have investigated the key interacting elements of PIB-SOs and PIB-SAs and their spatial conformation within the C-BS in order to confirm that the novel phenyl 2-imidazolidinone moiety of PIB-SOs and PIB-SAs can be used as a bioisosteric equivalent of the 3,4,5-trimethoxyphenyl haptophore (ring A) of CA-4 for the design of new, potent antimitotics. First, we clearly showed that Surflex-Dock ${ }^{\mathrm{TM}}$ was a good methodological approach to study the docking poses of various C-BS inhibitors upon binding to the C-BS. We next used T138067, ABT-751, colchicine and TN-16 to identify the key residues and their spatial conformations within the binding pockets of the C-BS. Three distinct pockets, i.e. I, II, and III and their main constituent amino acids were characterized. PIB-SO and PIB-SA derivatives were successfully docked into the C-BS using the Surflex-Dock ${ }^{\mathrm{TM}}$ software. PIB-SO was found to adopt 4 possible docking conformations within the C-BS as compared to PIB-SAs, which adopted 3 possible docking conformations. Docking conformations I and IV were common to the most strongly antitumoral PIB-SOs and PIB-SAs with high affinity for the C-BS. Finally, based on the different spatial conformations adopted by PIB-SOs and PIB-SAs in the C-BS, sulfonate and sulfonamide moieties were both shown to be bioisosteric equivalents of the ethenyl bridge of CA-4. In addition, and somewhat unexpectedly, our results suggested that the new phenyl 2-imidazolidinonyl moiety bound to the C-BS while adopting conformations different from that determined for $N$-phenyl- $N$ '-(2-chloroethyl)ureas (5a-5d) and their phenyl 2-aminooxazoline moieties $(\mathbf{6 a}, \mathbf{b})$, which had been described as bioisosteric equivalents of the 3,4,5-trimethoxy-phenyl moiety of CA-4, colchicine and a large number of antimitotics. Thus, the phenyl 2-imidazolidinonyl moiety was an interesting haptophoric entity that could be useful for the design of new potent antimitotics. 


\section{Experiment}

All calculations were performed using an SGI Onyx3800 supercomputer and Windows systems. The SYBYL molecular modeling software package was used to perform the QSAR analysis [52]. The Surflex-Dock ${ }^{\mathrm{TM}}$ software was used to construct the ProtoMol on the protein-binding surface. This software coated the binding surface of the protein with three types of probes that promoted potential hydrogen bond formation and hydrophobic interactions with protein atoms: 1) $\mathrm{CH}_{4}$ as a steric and hydrophobic probe; 2) $\mathrm{NH}$ as a hydrogen bond donor probe; and 3) $\mathrm{C}=\mathrm{O}$ as a hydrogen bond acceptor probe. A scoring function positioned and oriented the probes to optimize their interactions with the protein atoms. Only probes with the best scores were saved. Spatially redundant and isolated probes were pruned. Given that the score of each probe represented the contribution of that probe to protein-ligand binding affinity, clusters of high scoring probes identified the "stickiest" parts of the protein surface. Initial implementation with Surflex-Dock used the Hammerhead docking system to screen for the binding of flexible molecules to a protein-binding site. Surflex-Dock also used an empirically derived scoring function that was based on the binding affinity of the protein-ligand complexes and their X-ray structures. The Surflex-Dock scoring function was a weighted sum of non-linear functions involving van der Waals surface distances between the appropriate pairs of exposed protein and ligand atoms. Surflex-Dock scores were expressed in $-\log _{10}\left(K_{\mathrm{d}}\right)$ units to represent binding affinities.

\section{Acknowledgements}

This work is supported by the Canadian Institutes of Health Research (R.C.-G; Grant \#MOP-79334 and \# MOP-89707). We are indebted to Dr. Richard Poulin for his critical reading of the manuscript. S. Fortin was a recipient of a studentship from the Canadian Institutes of Health Research (CGD-83623). LPK acknowledges the support from Canada Foundation for Innovation.

\section{References}

[1] Mariotto, A.B., Yabroff, K.R., Shao, Y.W., Feuer, E.J. and Brown, M.L. (2011) Projections of the Cost of Cancer Care in the United States: 2010-2020. Journal of the National Cancer Institute, 103, 117-128. http://dx.doi.org/10.1093/jnci/djq495

[2] Bray, F., Jemal, A., Grey, N., Ferlay, J. and Forman, D. (2012) Global Cancer Transitions According to the Human Development Index (2008-2030): A Population-Based Study. The Lancet Oncology, 13, 790-801. http://dx.doi.org/10.1016/S1470-2045(12)70211-5

[3] International Agency for Research on Cancer, Cancer Research UK (2012) World Cancer Factsheet. Cancer Research UK, London.

[4] American Cancer Society (2015) Cancer Facts \& Figures 2015. American Cancer Society, Atlanta.

[5] Sawyer, T.K. (2004) Cancer Metastasis Therapeutic Targets and Drug Discovery: Emerging Small-Molecule Protein Kinase Inhibitors. Expert Opinion on Investigational Drugs, 13, 1-19.

[6] Sawyers, C. (2004) Targeted Cancer Therapy. Nature, 432, 294-297. http://dx.doi.org/10.1038/nature03095

[7] Oslund, K.L., Miller, L.A., Usachenko, J.L., Tyler, N.K., Wu, R. and Hyde, D.M. (2004) Oxidant-Injured Airway Epithelial Cells Upregulate Thioredoxin but Do Not Produce Interleukin-8. American Journal of Respiratory Cell and Molecular Biology, 30, 597-604. http://dx.doi.org/10.1165/rcmb.2002-02730C

[8] Tosoni, A., Ermani, M. and Brandes, A.A. (2004) The Pathogenesis and Treatment of Brain Metastases: A Comprehensive Review. Critical Reviews in Oncology/Hematology, 52, 199-215. http://dx.doi.org/10.1016/j.critrevonc.2004.08.006

[9] Wolf, M., Tebbe, S. and Fink, T. (2004) First-Line Chemotherapy in Metastatic Small-Cell Lung Cancer (SCLC). Lung Cancer, 45, S223-S234. http://dx.doi.org/10.1016/j.lungcan.2004.07.971

[10] Pouessel, D., Culine, S., Becht, C., Ychou, M., Romieu, G., Fabbro, M., Cupissol, D. and Pinguet, F. (2004) Gemcitabine and Docetaxel as Front-Line Chemotherapy in Patients with Carcinoma of an Unknown Primary Site. Cancer, 100, 1257-1261. http://dx.doi.org/10.1002/cncr.20100

[11] Gridelli, C., Rossi, A., Maione, P., Rossi, E., Castaldo, V., Sacco, P.C. and Colantuoni, G. (2009) Vascular Disrupting Agents: A Novel Mechanism of Action in the Battle against Non-Small Cell Lung Cancer. The Oncologist, 14, 612620. http://dx.doi.org/10.1634/theoncologist.2008-0287

[12] Kanthou, C. and Tozer, G.M. (2009) Microtubule Depolymerizing Vascular Disrupting Agents: Novel Therapeutic Agents for Oncology and Other Pathologies. International Journal of Experimental Pathology, 90, 284-294. http://dx.doi.org/10.1111/j.1365-2613.2009.00651.x 
[13] Patterson, D.M. and Rustin, G.J. (2007) Vascular Damaging Agents. Clinical Oncology (Royal College of Radiologists), 19, 443-456. http://dx.doi.org/10.1016/j.clon.2007.03.014

[14] Marrelli, M., Conforti, F., Statti, G.A., Cachet, X., Michel, S., Tillequin, F. and Menichini, F. (2011) Biological Potential and Structure-Activity Relationships of Most Recently Developed Vascular Disrupting Agents: An Overview of New Derivatives of Natural Combretastatin A-4. Current Medicinal Chemistry, 18, 3035-3081. http://dx.doi.org/10.2174/092986711796391642

[15] Berlin, J.D., Venook, A., Bergsland, E., Rothenberg, M., Lockhart, A.C. and Rosen, L. (2008) Phase II Trial of T138067, a Novel Microtubule Inhibitor, in Patients with Metastatic, Refractory Colorectal Carcinoma. Clinical Colorectal Cancer, 7, 44-47. http://dx.doi.org/10.3816/CCC.2008.n.006

[16] Meany, H.J., Sackett, D.L., Maris, J.M., Ward, Y., Krivoshik, A., Cohn, S.L., Steinberg, S.M., Balis, F.M. and Fox, E. (2010) Clinical Outcome in Children with Recurrent Neuroblastoma Treated with ABT-751 and Effect of ABT-751 on Proliferation of Neuroblastoma Cell Lines and on Tubulin Polymerization in Vitro. Pediatric Blood \& Cancer, 54, 4754. http://dx.doi.org/10.1002/pbc.22267

[17] Tron, G.C., Pirali, T., Sorba, G., Pagliai, F., Busacca, S. and Genazzani, A.A. (2006) Medicinal Chemistry of Combretastatin A4: Present and Future Directions. Journal of Medicinal Chemistry, 49, 3033-3044. http://dx.doi.org/10.1021/jm0512903

[18] Nam, N.H. (2003) Combretastatin A-4 Analogues as Antimitotic Antitumor Agents. Current Medicinal Chemistry, 10, 1697-1722. http://dx.doi.org/10.2174/0929867033457151

[19] Vincent, L., Kermani, P., Young, L.M., Cheng, J., Zhang, F., Shido, K., Lam, G., Bompais-Vincent, H., Zhu, Z., Hicklin, D.J., Bohlen, P., Chaplin, D.J., May, C. and Rafii, S. (2005) Combretastatin A4 Phosphate Induces Rapid Regression of Tumor Neovessels and Growth through Interference with Vascular Endothelial-Cadherin Signaling. The Journal of Clinical Investigation, 115, 2992-3006. http://dx.doi.org/10.1172/JCI24586

[20] Messaoudi, S., Treguier, B., Hamze, A., Provot, O., Peyrat, J.F., De Losada, J.R., Liu, J.M., Bignon, J., Wdzieczak-Bakala, J., Thoret, S., Dubois, J., Brion, J.D. and Alami, M. (2009) Isocombretastatins A versus Combretastatins A: The Forgotten isoCA-4 Isomer as a Highly Promising Cytotoxic and Antitubulin Agent. Journal of Medicinal Chemistry, 52, 4538-4542. http://dx.doi.org/10.1021/jm900321u

[21] Chaudhary, A., Pandeya, S.N., Kumar, P., Sharma, P.P., Gupta, S., Soni, N., Verma, K.K. and Bhardwaj, G. (2007) Combretastatin A-4 Analogs as Anticancer Agents. Mini Reviews in Medicinal Chemistry, 7, 1186-1205. http://dx.doi.org/10.2174/138955707782795647

[22] Hsieh, H.P., Liou, J.P. and Mahindroo, N. (2005) Pharmaceutical Design of Antimitotic Agents Based on Combretastatins. Current Pharmaceutical Design, 11, 1655-1677. http://dx.doi.org/10.2174/1381612053764751

[23] Shan, Y., Zhang, J., Liu, Z., Wang, M. and Dong, Y. (2011) Developments of Combretastatin A-4 Derivatives as Anticancer Agents. Current Medicinal Chemistry, 18, 523-538. http://dx.doi.org/10.2174/092986711794480221

[24] Lu, Y., Chen, J.J., Xiao, M., Li, W. and Miller, D.D. (2012) An Overview of Tubulin Inhibitors that Interact with the Colchicine Binding Site. Pharmaceutical Research, 29, 2943-2971. http://dx.doi.org/10.1007/s11095-012-0828-Z

[25] Gwaltney II , S.L., Imade, H.M., Li, Q., Gehrke, L., Credo, R.B., Warner, R.B., Lee, J.Y., Kovar, P., Frost, D., Ng, S.C. and Sham, H.L. (2001) Novel Sulfonate Derivatives: Potent Antimitotic Agents. Bioorganic \& Medicinal Chemistry Letters, 11, 1671-1673. http://dx.doi.org/10.1016/S0960-894X(01)00279-7

[26] Gwaltney II, S.L., Imade, H.M., Barr, K.J., Li, Q., Gehrke, L., Credo, R.B., Warner, R.B., Lee, J.Y., Kovar, P., Wang, J., Nukkala, M.A., Zielinski, N.A., Frost, D., Ng, S.C. and Sham, H.L. (2001) Novel Sulfonate Analogues of Combretastatin A-4: Potent Antimitotic Agents. Bioorganic \& Medicinal Chemistry Letters, 11, 871-874. http://dx.doi.org/10.1016/S0960-894X(01)00098-1

[27] Ducki, S., Mackenzie, G., Greedy, B., Armitage, S., Chabert, J.F., Bennett, E., Nettles, J., Snyder, J.P. and Lawrence, N.J. ( 2009) Combretastatin-Like Chalcones as Inhibitors of Microtubule Polymerisation. Part 2: Structure-Based Discovery of $\alpha$-Aryl Chalcones. Bioorganic \& Medicinal Chemistry, 17, 7711-7722.

[28] Ducki, S., Rennison, D., Woo, M., Kendall, A., Chabert, J.F., McGown, A.T. and Lawrence, N.J. (2009) Combretastatin-Like Chalcones as Inhibitors of Microtubule Polymerization. Part 1: Synthesis and Biological Evaluation of Antivascular Activity. Bioorganic \& Medicinal Chemistry, 17, 7698-7710. http://dx.doi.org/10.1016/j.bmc.2009.09.039

[29] Wang, L., Woods, K.W., Li, Q., Barr, K.J., McCroskey, R.W., Hannick, S.M., Gherke, L., Credo, R.B., Hui, Y.H., Marsh, K., Warner, R., Lee, J.Y., Zielinski-Mozng, N., Frost, D., Rosenberg, S.H. and Sham, H.L. (2002) Potent, Orally Active Heterocycle-Based Combretastatin A-4 Analogues: Synthesis, Structure-Activity Relationship, Pharmacokinetics, and in Vivo Antitumor Activity Evaluation. Journal of Medicinal Chemistry, 45, 1697-1711. http://dx.doi.org/10.1021/jm010523x

[30] Romagnoli, R., Baraldi, P.G., Cruz-Lopez, O., Lopez Cara, C., Carrion, M.D., Brancale, A., Hamel, E., Chen, L., Bortolozzi, R., Basso, G. and Viola, G. (2010) Synthesis and Antitumor Activity of 1,5-Disubstituted 1,2,4-Triazoles as Cis-Restricted Combretastatin Analogues. Journal of Medicinal Chemistry, 53, 4248-4258.

http://dx.doi.org/10.1021/jm100245q 
[31] Akselsen, O.W., Odlo, K., Cheng, J.J., Maccari, G., Botta, M. and Hansen, T.V. (2012) Synthesis, Biological Evaluation and Molecular Modeling of 1,2,3-Triazole Analogs of Combretastatin A-1. Bioorganic \& Medicinal Chemistry, 20, 234242. http://dx.doi.org/10.1016/j.bmc.2011.11.010

[32] Kim, Y., Nam, N.H., You, Y.J. and Ahn, B.Z. (2002) Synthesis and Cytotoxicity of 3,4-Diaryl-2(5H)-Furanones. Bioorganic \& Medicinal Chemistry Letters, 12, 719-722. http://dx.doi.org/10.1016/S0960-894X(01)00831-9

[33] Ohsumi, K., Hatanaka, T., Fujita, K., Nakagawa, R., Fukuda, Y., Nihei, Y., Suga, Y., Morinaga, Y., Akiyama, Y. and Tsuji, T. (1998) Syntheses and Antitumor Activity of Cis-Restricted Combretastatins: 5-Membered Heterocyclic Analogues. Bioorganic \& Medicinal Chemistry Letters, 8, 3153-3158. http://dx.doi.org/10.1016/S0960-894X(98)00579-4

[34] Fortin, J.S., Cote, M.-F., Lacroix, J., Desjardins, M., Petitclerc, E. and C.-Gaudreault, R. (2008) Selective Alkylation of $\beta_{\mathrm{II}}$-Tubulin and Thioredoxin-1 by Structurally Related Subsets of Aryl Chloroethylureas Leading to either Anti-Microtubules or Redox Modulating Agents. Bioorganic \& Medicinal Chemistry, 16, 7277-7290. http://dx.doi.org/10.1016/j.bmc.2008.06.028

[35] Fortin, J.S., Lacroix, J., Desjardins, M., Patenaude, A., Petitclerc, E. and C.-Gaudreault, R. (2007) Alkylation Potency and Protein Specificity of Aromatic Urea Derivatives and Bioisosteres as Potential Irreversible Antagonists of the Colchicine-Binding Site. Bioorganic \& Medicinal Chemistry, 15, 4456-4469. http://dx.doi.org/10.1016/j.bmc.2007.04.028

[36] Fortin, S., Bouchon, B., Chambon, C., Lacroix, J., Moreau, E., Chezal, J.-M., Degoul, F. and C.-Gaudreault, R. (2011) Characterization of the Covalent Binding of $N$-Phenyl- $N$ '-(2-chloroethyl)ureas to $\beta$-Tubulin: Importance of Glutamic Acid 198 in Microtubule Stability. The Journal of Pharmacology and Experimental Therapeutics, 336, 460-467. http://dx.doi.org/10.1124/jpet.110.171082

[37] Fortin, S., Moreau, E., Lacroix, J., Teulade, J.-C., Patenaude, A. and C.-Gaudreault, R. (2007) N-Phenyl- $N$ '-(2-chlo- roethyl)urea Analogues of Combretastatin A-4: Is the $N$-Phenyl- $N$ '-(2-chloroethyl)urea Pharmacophore Mimicking the Trimethoxy Phenyl Moiety? Bioorganic \& Medicinal Chemistry Letters, 17, 2000-2004. http://dx.doi.org/10.1016/j.bmcl.2007.01.023

[38] Fortin, S., Moreau, E., Patenaude, A., Desjardins, M., Lacroix, J., Rousseau, J.L. and C.-Gaudreault, R. (2007) $N$-Phenyl- $N$ '-(2-chloroethyl)ureas (CEU) as Potential Antineoplastic Agents. Part 2: Role of $\omega$-Hydroxyl Group in the Covalent Binding to $\beta$-Tubulin. Bioorganic \& Medicinal Chemistry, 15, 1430-1438. http://dx.doi.org/10.1016/j.bmc.2006.11.005

[39] Fortin, S., Wei, L., Moreau, E., Labrie, P., Petitclerc, E., Kotra, L.P. and C.-Gaudreault, R. (2009) Mechanism of Action of $N$-Phenyl- $N$ '-(2-chloroethyl)ureas in the Colchicine-Binding Site at the Interface between $\alpha$ - and $\beta$-Tubulin. Bioorganic \& Medicinal Chemistry, 17, 3690-3697. http://dx.doi.org/10.1016/j.bmc.2009.03.056

[40] Fortin, S., Labrie, P., Moreau, E., Wei, L., Kotra, L.P. and C.-Gaudreault, R. (2008) A Comparative Molecular Field and Comparative Molecular Similarity Indices Analyses (CoMFA and CoMSIA) of $N$-Phenyl- $N$ '-(2-chloroethyl)ureas Targeting the Colchicine-Binding Site as Anticancer Agents. Bioorganic \& Medicinal Chemistry, 16, 1914-1926. http://dx.doi.org/10.1016/j.bmc.2007.11.004

[41] Moreau, E., Fortin, S., Desjardins, M., Rousseau, J.L., Petitclerc, E. and C.-Gaudreault, R. (2005) Optimized $N$-Phenyl-N'-(2-chloroethyl)ureas as Potential Antineoplastic Agents: Synthesis and Growth Inhibition Activity. Bioorganic \& Medicinal Chemistry, 13, 6703-6712. http://dx.doi.org/10.1016/j.bmc.2005.07.048

[42] Moreau, E., Fortin, S., Lacroix, J., Patenaude, A., Rousseau, J.L. and C.-Gaudreault, R. (2008) N-Phenyl-N’(2-chloroethyl)ureas (CEUs) as Potential Antineoplastic Agents. Part 3: Role of Carbonyl Groups in the Covalent Binding to the Colchicine-Binding Site. Bioorganic \& Medicinal Chemistry, 16, 1206-1217. http://dx.doi.org/10.1016/j.bmc.2007.10.078

[43] Fortin, S., Wei, L., Moreau, E., Lacroix, J., Côté, M.-F., Petitclerc, E., Kotra, L.P. and C.-Gaudreault, R. (2011) Design, Synthesis, Biological Evaluation, and Structure-Activity Relationships of Substituted Phenyl 4-(2-Oxoimidazolidin-1yl)benzenesulfonates as New Tubulin Inhibitors Mimicking Combretastatin A-4. Journal of Medicinal Chemistry, 54, 4559-4580. http://dx.doi.org/10.1021/jm200488a

[44] Fortin, S., Wei, L., Moreau, E., Lacroix, J., Cote, M.-F., Petitclerc, E., Kotra, L.P. and C.-Gaudreault, R. (2011) Substituted Phenyl 4-(2-Oxoimidazolidin-1-yl)benzenesulfonamides as Antimitotics. Antiproliferative, Antiangiogenic and Antitumoral Activity, and Quantitative Structure-Activity Relationships. European Journal of Medicinal Chemistry, 46, 5327-5342. http://dx.doi.org/10.1016/j.ejmech.2011.08.034

[45] Ruppert, J., Welch, W. and Jain, A.N. (1997) Automatic Identification and Representation of Protein Binding Sites for Molecular Docking. Protein Science, 6, 524-533. http://dx.doi.org/10.1002/pro.5560060302

[46] Dorleans, A., Gigant, B., Ravelli, R.B., Mailliet, P., Mikol, V. and Knossow, M. (2009) Variations in the ColchicineBinding Domain Provide Insight into the Structural Switch of Tubulin. Proceedings of the National Academy of Sciences of the United States of America, 106, 13775-13779. http://dx.doi.org/10.1073/pnas.0904223106

[47] Ravelli, R.B., Gigant, B., Curmi, P.A., Jourdain, I., Lachkar, S., Sobel, A. and Knossow, M. (2004) Insight into Tubulin Regulation from a Complex with Colchicine and a Stathmin-Like Domain. Nature, 428, 198-202. http://dx.doi.org/10.1038/nature02393 
[48] Nguyen, T.L., McGrath, C., Hermone, A.R., Burnett, J.C., Zaharevitz, D.W., Day, B.W., Wipf, P., Hamel, E. and Gussio, R. (2005) A Common Pharmacophore for a Diverse Set of Colchicine Site Inhibitors Using a Structure-Based Approach. Journal of Medicinal Chemistry, 48, 6107-6116. http://dx.doi.org/10.1021/jm050502t

[49] Tripathi, A., Durrant, D., Lee, R.M., Baruchello, R., Romagnoli, R., Simoni, D. and Kellogg, G.E. (2009) Hydropathic Analysis and Biological Evaluation of Stilbene Derivatives as Colchicine Site Microtubule Inhibitors with Anti-Leukemic Activity. Journal of Enzyme Inhibition and Medicinal Chemistry, 24, 1237-1244. http://dx.doi.org/10.3109/14756360902787055

[50] Hu, L., Li, Z.R., Li, Y., Qu, J., Ling, Y.H., Jiang, J.D. and Boykin, D.W. (2006) Synthesis and Structure-Activity Relationships of Carbazole Sulfonamides as a Novel Class of Antimitotic Agents against Solid Tumors. Journal of Medicinal Chemistry, 49, 6273-6282. http://dx.doi.org/10.1021/jm060546h

[51] Zhou, J., Zhang, Y., Cui, Y.W., Li, Z.M., Song, H.R., Dong, J.H., Chen, X.G. and Xu, B.L. (2011) Synthesis and Cytotoxic Evaluation of $N$-(4-Methoxy-1H-benzo[d]imidazol-7-yl)-arylsulfonamide and $N$-Aryl-(4-methoxy-1H-benzo [d]imidazol)-7-sulfonamide Analogs of Combretastatin A-4. Journal of Asian Natural Products Research, 13, 330-340. http://dx.doi.org/10.1080/10286020.2011.556091

[52] SYBYL. 8.1, Tripos International, 1699 South Hanley Rd., St. Louis, Missouri, 63144, USA.

\section{Abbreviations List}

VDAs: vascular disrupting agents;

CA4-P: combretastatin A-4 disodium phosphate;

CA-4: combretastatin A-4;

C-BS: colchicine-binding site;

PDB: protein data bank;

PIB-SO: phenyl 4-(2-oxoimidazolidin-1-yl)benzene- sulfonate;

PIB-SA: phenyl 4-(2-oxoimidazolidin-1-yl)benzenesulfonamide. 